\title{
Climate Change on Glaciers and the Current Approach of Protecting the Glaciers
}

\author{
Meirui Qian \\ College of Natural Science, Physiology Department, Michigan State University, East Lansing, MI, 48823 USA \\ *Corresponding author.Email:qianmei1@msu.edu
}

\begin{abstract}
Climate change has a significant impact on health's social and environmental determinants. It's frequently linked to our environment and man-made stressors, both of which have already had an impact on public health in a variety of ways. Climate change has a direct impact on our basic needs for clean air, clean water, sufficient food, and safe shelter. Global warming, rising sea levels, extreme weather, natural disasters, and other new health-related threats are all becoming more prevalent in our daily lives. These effects appeared to be unrelated at first, but they are in fact intertwined. Global warming has now overtaken all of the other threats as the most serious issue in almost every country. Icebergs and glaciers may melt as a result of global warming, raising sea levels, and there are theories that more ancient viruses and animal corpses are being discovered. On a long-term scale, the problems and damage that come with environmental issues are harmful to humans.
\end{abstract}

Keywords: Climate change, glaciers, global warming, rising of sea-level

\section{INTRODUCTION}

The rising level of ground-level ozone and other particulate matter produced by industries is causing respiratory diseases such as decreased lung function, [1] asthma, and premature death. Elders, children, and those with respiratory diseases are the target victims. Extreme weather events can include heavy rain, hurricane, tornado, and flood. Each of these events has the potential to injure coastal populations, and damage [2] can occur in city power plants, resulting in a fire. Water quality can be affected by climate change, the increasing average temperature and frequency and intensity of storming can affect drinking and [5] recreational water quality, which can cause chronic diseases. Increasing ground-level ozone and particulate matter will increase the probability for people to have a respiratory illness. The "disappearing" of glaciers has not been stressed enough.

Glacier's social, economic, and environmental significance have motivated several countries to regulate activities on glaciated areas and their surroundings. However, these have not been the trend since governments had not yet considered Glacier's associated significance. As a result, recent trends in glacier protection have forced different countries in the contemporary world to ratify laws specifically for protecting mountain glaciers. These laws protecting glaciated areas have therefore been considered within the national political agendas. The policies are known to originate from those countries where mining activities are posing a significant threat to the glacial damage with the aim of guarding the cryosphere against such destructive undertakings. In the paper, I am analyzing the current approach to glacier protection. Among the identified recent measures include the policies passed by different nations and the strategies put in action to curb climatic change, which is a significant threat to glaciers.

\section{THE IMPORTANCE OF GLACIERS}

\subsection{Functions of Glaciers}

Ice sheets can reflect the sunlight up to $80 \%$, while ice water can only reflect $20 \%$ of the sunlight. That is, glaciers can function to lower the temperature of the earth, thereby regulating global climate. Glaciers is the most important form of fresh water on earth. There are more than 16 million square kilometers of glaciers on earth, covering $11 \%$ of the continent, and four-fifths of earth's freshwater resource. Glacier provides vital ecosystem services such as water storage and regulation of runoffs. As a result, its significance is widely recognized in the socioeconomic and the environment. For example, Glacier represents an economic asset that 
benefits agriculture and hydropower sectors [6]. Besides, glacierized environments attract tourists who bring about revenues to the host countries and across the globe [7]. Nevertheless, in appreciation of the economic significance of glaciers, different countries have been motivated to ratify policies that protect glaciers from potentially dangerous undertakings. Even though Glacier is known for its socioeconomic and environmental significance, destructive geomorphic and hydrologic processes have been experienced in the glaciated areas. For example, dangerous occurrences such as glacier lake blast inundations may be triggered by sudden or steady variations in glacier diminuendos [6]. The impact is therefore felt from the resultant damages in the downstream areas. For safety purposes and protection of the associated benefits of Glacier, several measures have been put in place [8]. The measures are put in place to protect those activities which trigger the dynamic changes in Glacier.

\subsection{Impacts of Glaciers'Melting and Damage}

Changing in glaciers also have a significant impact on the heat balance of the earth's surface, atmospheric circulation, and ocean currents. Due to the strong reflection effect of snow and ice on solar radiation, the large-scale change of glacier area will cause the imbalance of surface radiation and heat, which will lead to the change of atmospheric circulation. The amount of cold water being released into the ocean from the massive melting of polar ice caps will alter current patterns in such a way as to alter the interaction between the ocean and atmosphere, thus affecting global climate. For example, the Antarctic ice sheet is the main source of coldness on the Earth. It is like a huge "condenser" located in the southernmost part of the earth, cooling the hot air that came from the equator, regulating the global heat balance. Ice shelves and ice barriers form as Antarctic continental ice sheets slide down mountain slopes toward sea ice. Icebergs form when continental ice breaks off from ice shelves into the sea. The formation and loss of icebergs, as well as the number of icebergs, affect the temperature of the Southern Ocean, leading to changes in the thermal balance system, and thus the global climate.

Some have suggested that the melting of icebergs and glaciers could potentially release ancient viruses, and since some animal corpuses from ancient times have been discovered, more virus and unexpected biochemicals will be released. According to a new study published in "Nature", temperatures in the Arctic area have risen two to three times faster than anywhere else on Earth, and the 21 st century could be the warmest period of time in 115,000 years. Rising temperatures in the Arctic are having a chain effect, it could potentially activate some of the factors that drive the spread of viruses, making the virus crisis take on more complex forms than ever before. Rising temperatures in the Arctic are melting the ice and the permafrost of land, where ancient viruses have been trapped for millions of years. Moreover, the melting of the ice that covers the Arctic oceans has allowed creatures living in the Atlantic and Pacific region to merge. Before the ice melted, creatures in those two regions were separated by thick Arctic ice and formed relatively separate genetic systems, each region is lacking antibodies to the other's diseases. And the loss of the ice will bring together these native creatures that used to live in different areas and carry different and more complex diseases, which will inevitably lead to the spread of some deadly diseases. The existence of global warming is forcing some species of wildlife to move to areas that were previously too cold for animals to live in. It is conceivable that the habitat of a large number of migratory birds around the world will also change due to climate change, which will change the migratory behavior of bird species. This change will allow more opportunities for the spread of human-avian co-infection viruses, such as avian influenza. Although the arctic is a desolate, deep permafrost layer can be a safe corner, but the human has begun to carry out scientific research and production activities in these regions, mining and drilling operations could make this ancient permafrost exposed, if the dynamic virus particles are still active, the consequences are unmeasurable.

\section{STATUS QUO OF GLACIERS PROTECTION AND OUR APPROACH}

Although there are numerous suggestions out there that are trying to solve or somewhat alleviate the issue, it is still very hard to carry out actual plans. This is an issue that we cannot palpate, therefore, it is very hard to find a long-term solution to actually resolve this global phenomenon.

Every plan needs a first step. For us, raising awareness is what we should be doing as a starter. City and community organizations can hold events educating residents on such issues, establishing the foundation can help build awareness. With professionals regularly anticipating the climate impacts and vulnerabilities, people can get a better scope of what are the impacts, what are some [3] potential outcomes, and that populations and locations are vulnerable. Since now we have so many social media dedicating the global phenomenon, many platforms would be a great resource.

According to Washington News, in June 2021, current policies are in place to reduce the black carbon deposits that trigger the glaciers' dynamic changes [9]. Among the set standards include measures to enhance fuel safety, doing away with diesel vehicles while promoting electric cars, and improving the efficiency of brick kilns help reduce black carbon deposits by about $23 \%$ [9]. However, that is not enough to ensure safety 
from the hazardous impacts of glaciers. As a result, the environmental analysts and weather analysts have called for the regional corporation to help protect the resources and the health of people. Therefore, there is a need for every individual to take measures to protect the extent of glaciers melting by ensuring environmental safety. Additionally, countries in South Asia are forced to manage the hydropower resource by comprehensively addressing the challenges associated with the melting glaciers along the mountains of the Himalayas. For example, in Argentina, a law to safeguard glaciers and the peripheral environs was decreed in 2014 [6]. Similar laws were also debated in Chile and Kyrgyzstan legislatures. These laws are premeditated to secure the glacial environment from activities that can destroy the glacier ice, bring about contaminations in the water supplies, and threaten the aesthetic value of the mountainous areas. Among these activities include mining and natural resource extractions.

Since Glacier responds rapidly to climate change resulting in hazardous impacts on the surrounding environments, measures to regulate climatic changes have been put in place to protect Glacier [8]. For example, a treaty to regulate waste disposal and other economic activities resulting in climate change has been enacted [6]. Furthermore, in Canada and Ecuador, national parks are mandated to regulate the activities developed on Glacier and its surroundings, even though the legislation does not explicitly mention Glacier [8]. Nevertheless, regulations affecting glaciers do vary in different states. However, water is considered public property in most countries and is thus used commonly by all residents. Regardless of the above mentioned policies from different states, it is rare to obtain specific glacier regulations. In Switzerland, for instance, cable cars are only encouraged on glaciers situated close to major tourist townships when glaciers prolong during ski seasons [10]. Therefore, in most cases, Glacier regulations are embedded in environmental laws, water regulation policies, and regional planning strategies. Recently, governments have taken the mandate to regulate Glacier. As a result, national laws have been specifically made to protect glaciers where they have been considered under political agendas [10]. The formulation of the rules was motivated by the continuous environmental conflicts resulting from the mining activities along the ice-capped mountains. The approval of ecological policies in Argentina was drafted directly to protect both socioeconomic and political conflicts.

The jurisdiction of the laws in different countries is expressed with interest in protecting the environment. for instance, the Argentina laws 2010 covers glaciers and permafrost areas where it allows the edifice of infrastructure to avert hazards on the environment. Chile's laws were submitted in May 2016 to protect Glacier and glaciated areas and the surroundings from the glacier fronts. However, the debate is still underway
[7]. The Kyrgyzstan law was enacted in 2014 to protect the glaciers, zones of permafrost, and snowfields. The law was approved by the parliament, where the president voted it. However, the identified measures have presented several omissions. For instance, they do not recognize the glacial and permafrost-related hazards [8]. Furthermore, the associated policies only focused on the strategies that influence the environment surrounded by glaciers by regulating the activities. A more precise technique to help protect glaciers adopted most recently is the mechanical ice quarry, melting and castigating [6]. The methods have been utilized by manufacturing schemes in the peak regions and have shown improvement in preventing damages from glaciers in draining ice obstructed lakes [10]. Research reports reveal that the techniques have a direct effect on the bulk of Glacier and its undercurrents.

\section{CONCLUSION}

In conclusion, the glacier provides vibrant biome services such as water storage and direct runoff. However, regardless of the positive impacts of Glacier, it has posed significant threats to both the environment and the general ecosystem. As a result, measures have been taken to protect the glacier and prevent the hazardous impacts of its dynamics. Among the identified measures include the national laws, which help protect the surroundings of glaciated areas and regulate the activities around the glaciated regions. Besides, different parliaments, including Argentina and Chile, have enacted various laws to govern glacial activities and the environment. Future analysis will focus on how climate change impacts global conditions and how glaciers' current situation would cause link reactions.

\section{ACKNOWLEDGMENT}

I want to take this chance to express my appreciation to my university, Michigan State University. Through four years of my college life, all of my professors and my advisor in the department showed me enormous support and kindness. They gave me courage, not only in my academic performance, but also in my life as a student. My research professor, Dr. William Trochim, showed me how to use a professional manner to outline the paper. During the studying process, Dr. Trochim gave me useful tips to finalize my very first attempt at this paper. I also want to thank my paper consolers, who have been the greatest help through all the process. Finally, I want to thank my family and friends-Leno, Ke, Zora, and Eleanor-for all their support and love.

\section{REFERENCES}

[1] Centers for Disease Control and Prevention. (2021). Climate Effects on Health: Air Pollution. 
https://www.cdc.gov/climateandhealth/effects/air_ pollution.htm .

[2] Centers for Disease Control and Prevention. (2019). Climate Change and Public Health - CDC Policy. https://www.cdc.gov/climateandhealth/policy.htm .

[3] United States Environmental Protection Agency. (2020). Implications of Climate Change. https://www.epa.gov/arc-x/implications-climatechange .

[4] Wu Jie, Zhihu. (2014). Can Car Restrictions Make Contribution to Prevent Smog? https://www.zhihu.com/question/22375822 .

[5] United States Environmental Protection Agency. (2020). Public Health Adaptation Strategies for Climate Change. https://www.epa.gov/arc$\mathrm{x} /$ public-health-adaptation-strategies-climatechange .

[6] Anacona, P. I., Kinney, J., Schaefer, M., Harrison, S., Wilson, R., Segovia, A., ... \& Glasser, N. F. (2018). Glacier protection laws: Potential conflicts in managing glacial hazards and adapting to climate change. Ambio, 47(8), 835-845.

[8] Hussain, M., Butt, A. R., Uzma, F., Ahmed, R., Irshad, S., Rehman, A., \& Yousaf, B. (2020). A comprehensive review of climate change impacts, adaptation, and mitigation on environmental and natural calamities in Pakistan. Environmental monitoring and assessment, 192(1), 1-20.

[7] Rai, S. C., \& Gurung, T. (2015). An overview of glaciers, glacier retreat, and subsequent impacts in Nepal, India, and China.

[9] Zhongming, Z., Linong, L., Wangqiang, Z., \& Wei, L. (2021). Glaciers of the Himalayas World Bank Report.

[10] Aggarwal, A., Frey, H., McDowell, G., Drenkhan, F., Nüsser, M., Racoviteanu, A., \& Hoelzle, M. (2021). Adaptation to climate change-induced water stress in major glacierized mountain regions. Climate and Development, 1-13.

[11] Xinhuanet. (2020). The virus's ice cell is melting. http://www.xinhuanet.com/globe/202008/18/c_139296713.htm .

[12] (n.d). The Impact of Global Climate Change on Glaciers.

https://m.lunwendata.com/show.php?id=23844 